\title{
DNA degradation in avian faecal samples and feasibility of non-invasive genetic studies of threatened capercaillie populations
}

\author{
Sébastien Regnaut ${ }^{1, *}$, Françoise S. Lucas ${ }^{1,2}$ \& Luca Fumagalli ${ }^{1}$ \\ ${ }^{1}$ Department of Ecology and Evolution, Laboratory for Conservation Biology, University of Lausanne, \\ CH-1015 Lausanne, Switzerland; ${ }^{2} E A W A G$, Limnological Research Center, CH-6047 Kastanienbaum, \\ Switzerland (*Corresponding author: Phone: +41-21-6924172; Fax:+41-21-6924165; E-mail: sreghaut@, \\ excite.com)
}

Received 29 June 2005; accepted 6 July 2005

Key words: bird, DNA degradation, faeces, genotyping errors, microsatellites, non-invasive sampling

\begin{abstract}
We evaluated the feasibility of using faeces as a non-invasively collected DNA source for the genetic study of an endangered bird population (capercaillie; Tetrao urogallus). We used a multitube approach, and for our panel of 11 microsatellites genotyping reliability was estimated at $98 \%$ with five repetitions. Experiments showed that free DNases in faecal material were the major cause of DNA degradation. Our results demonstrate that using avian faeces as a source of DNA, reliable microsatellite genotyping can be obtained with a reasonable number of PCR replicates.
\end{abstract}

\section{Introduction}

Non-invasive genetic sampling strategies, using DNA sources such as faeces, hair or feathers, have greatly increased the scope of conservation genetic studies (e.g. Taberlet et al. 1999). However, there are problems with samples obtained non-invasively. For example, DNA can be degraded, PCR inhibitors can be present and incorrect genotypes can arise because of allelic dropout (ADO) and/or false alleles (FA) (Taberlet et al. 1996). Faecal samples have been used fairly extensively in mammals for microsatellite analysis (reviewed in Broquet and Petit 2004), in contrast, there has only been one study of birds (Segelbacher and Steinbrück 2001), and there is no information on the genotyping error rates from avian faecal samples. In this study, we estimated the genotyping reliability using faeces collected from wild capercaillie (Tetrao urogallus) in the Swiss and French Jura. We also compared experimentally the relative contribution of hydro- lytic, enzymatic and microbial activities in faecal DNA degradation.

\section{Material and methods}

Faeces were collected individually in labelled plastic bags. In the laboratory, samples were dried on absorbent paper sheets for 3 days. Dried faeces were transferred into plastic vials containing silica gel beads and stored at room temperature for between 3 days and 4 years before DNA isolation.

DNA was extracted in a laboratory dedicated to low-copy DNA analysis. We used the QIAamp DNA stool kit (Qiagen), with twice the amount of sample and reactants indicated by the manufacturer. Approximately $200 \mathrm{mg}$ of dry faeces were placed in two $2 \mathrm{ml}$ tubes, and $1.6 \mathrm{ml}$ of ASL lysis buffer (Qiagen) were added to each of the two tubes. After vortexing and centrifugation, the supernatant of both duplicates was transferred into 
a single new $2 \mathrm{ml}$ tube containing the adsorbing matrix provided in the kit. After centrifugation, the supernatant was split again in two new $2 \mathrm{ml}$ tubes containing AL lysis buffer and proteinase $\mathrm{K}$ and incubated at $70{ }^{\circ} \mathrm{C}$ for $10 \mathrm{~min}$. Ethanol was then added and the solution transferred into a single Qiagen column at a maximum of $700 \mu \mathrm{l}$ at a time. This step was repeated until all the solution had been passed through the column. The column was washed twice with washing buffers, and the bound DNA eluted in $375 \mu \mathrm{l}$ of elution buffer. Tubes without faecal material were included in each extraction session as negative controls.

Amplification success was assessed using 85 randomly chosen samples (together with a positive control made of a highly diluted capercaillie liver DNA), and two successive amplifications of the TTT1 microsatellite locus (see below). Samples that failed to amplify were re-extracted and tested until successful PCR amplification or until four extraction attempts. To determine sex, we designed two reverse primers located on each sex-chromosome (TuWR: 5'-TAATCAGAGCAACCTGAATGC-3'; TuZR: 5'-GGAATGTTAACATACTC CTTCACA-3') that were used with the forward primer 2550F (Fridolfsson and Ellegren 1999). Amplifications were carried out in a total volume of $25 \mu \mathrm{l}$, containing $1 \times$ PCR reaction buffer, $2.5 \mathrm{mM} \mathrm{MgCl} 2,0.15 \mathrm{mg} / \mathrm{ml} \mathrm{BSA}, 0.5-1$ unit Gold Taq DNA polymerase (Applied Biosystems), $5 \mu \mathrm{l}$ template DNA, $0.1 \mathrm{mM}$ of each dNTPs and $0.3-$ $0.6 \mu \mathrm{M}$ of each of the three primers. The cycling parameters were: initial $\mathrm{Taq}$ activation at $96^{\circ} \mathrm{C}$ for $3 \mathrm{~min}$, followed by 10 touch-down cycles (from 60 to $50{ }^{\circ} \mathrm{C}$ ), then 40 additional cycles with denatur- ation at $94{ }^{\circ} \mathrm{C}$, annealing at $53{ }^{\circ} \mathrm{C}$ and elongation at $72{ }^{\circ} \mathrm{C}$, all $45 \mathrm{~s}$ long.

A total of 57 faecal samples randomly-chosen out of the whole set of faeces sampled in the field were genotyped using 11 microsatellite markers (Table 1) amplified in $20 \mu \mathrm{l}$ of the same reaction mix as above. In negative controls, DNA template was replaced by $5 \mu \mathrm{l}$ nanopore water. After initial denaturation at $96{ }^{\circ} \mathrm{C}$ for $3 \mathrm{~min}, 45-55$ cycles were conducted with 45 s steps: denaturation at $94^{\circ} \mathrm{C}$, annealing at $59^{\circ} \mathrm{C}$ and elongation at $72^{\circ} \mathrm{C}$. Amplification products were electrophoresed on a ABI377 automated sequencer. Diluted liver DNA was used for PCR positive control and allele-size reference across gels.

To estimate allelic dropout (ADO), false allele (FA) rates and probability of identity (PI), we repeatedly genotyped each sample six times and used the software Gimlet (Valière 2002). Consensus genotypes were scored as heterozygous when both alleles appeared at least twice and homozygous when identical alleles appeared at least 4 times among the 6 replicates. Allele frequencies and heterozygosities were calculated using FSTAT (Goudet 1995), and used in the software Gemini (Valière et al. 2002) to estimate the probability of exact genotyping with 2-10 replicates.

To identify the potential causes of DNA degradation, we set up four experimental treatments: "Biotic", "Hydrolytic", "Enzymatic" and "Microbial" (Figure 1). Briefly, faecal material from five individuals (two males and three females) was dried for $24 \mathrm{~h}$ at $65^{\circ} \mathrm{C}$ (we pooled faeces from several individuals to have enough material for replicates and treatments, and to

Table 1. Per locus error rates

\begin{tabular}{|c|c|c|c|c|c|c|c|c|c|c|c|c|c|}
\hline & TTD2 & TUT2 & TTD6 & TTD1 & TTT1 & TUT4 & TUD3 & TUT1 & TUD1 & TUD5 & TUT3 & Mean & $\mathrm{SD}$ \\
\hline nb PCR & 342 & 342 & 342 & 342 & 342 & 342 & 342 & 342 & 342 & 342 & 342 & 342 & \\
\hline$\%$ failed & 8.19 & 2.63 & 3.51 & 18.13 & 15.2 & 13.45 & 7.89 & 4.39 & 14.62 & 14.91 & 13.16 & 10.55 & 5.41 \\
\hline $\mathrm{ADO}$ & 0.17 & 0.24 & 0.11 & 0.26 & 0.19 & 0.28 & 0.10 & 0.20 & 0.22 & 0.26 & 0.28 & 0.21 & 0.06 \\
\hline FA & 0.09 & 0.04 & 0.03 & 0.01 & 0.01 & 0.00 & 0.03 & 0.03 & 0.03 & 0.01 & 0.01 & 0.03 & 0.02 \\
\hline PI & 0.07 & 0.09 & 0.11 & 0.12 & 0.14 & 0.19 & 0.20 & 0.25 & 0.26 & 0.39 & 0.59 & 6.6E-09 & \\
\hline $\mathrm{PI}(s i b)$ & 0.38 & 0.41 & 0.42 & 0.43 & 0.45 & 0.49 & 0.48 & 0.53 & 0.55 & 0.62 & 0.78 & 4.2E-04 & \\
\hline PI rank & 1 & 2 & 3 & 4 & 5 & 6 & 7 & 8 & 9 & 10 & 11 & & \\
\hline
\end{tabular}

nb PCR: total number of PCRs conducted on 57 samples (with 6 repetitions); \% failed: proportion of PCRs for which no signal was detected on the automated sequencer; ADO: allelic dropout rate; FA: false allele rate; PI: probability of identity; PI(sib): PI if individuals of focus are sibs; PI rank: loci are ranked according to the lower PI (see text for further details). TUT and TUD microsatellites designed for T. urogallus from Segelbacher et al. (2000); TTD and TTT microsatellites designed for T. tetrix from Caizergues et al. (2001). 
avoid confounding effects such as sex, origin and sample age). Homogenised, dry faeces ( $89 \mathrm{~g}$ ) were mixed with $870 \mathrm{ml}$ of autoclaved phosphate saline buffer ( $\mathrm{pH}$ 7.2) and the solid and liquid phases separated by filtration (LS 141/2, Schleicher \& Schluer). The liquid phase was divided into four: (i) "Biotic" treatment (hydrolysis, enzymatic and microbial factors): faecal liquid was untreated; (ii) "Hydrolysis" treatment (no enzymes and microorganisms): faecal liquid was autoclaved; (iii) "Enzymatic" treatment (no microorganisms): faecal liquid was filtered through $0.2 \mu \mathrm{m}$ cellulose acetate membrane (Whatman); (iv) "Microbial" treatment (no enzymes): faecal liquid was filtered through $0.2 \mu \mathrm{m}$ cellulose acetate membrane, and microorganisms trapped on the filter were then resuspended in the heated faecal filtrate $(10 \mathrm{~min}$ at $90{ }^{\circ} \mathrm{C}$ to denature DNases) with $5 \mathrm{~min}$ in an ultrasonic bath (Telsonic ultrasonics). Three $\mathrm{ml}$ of these four differently treated liquid phases were then mixed in separate $15 \mathrm{ml}$ Falcon tubes with $0.5 \mathrm{~g}$ of autoclaved solid material $(20 \mathrm{~min}$ at $120^{\circ} \mathrm{C}$ ) and $1.1 \mu \mathrm{g}$ of capercaillie liver DNA (see Figure 1). For each treatment we set up four replicates and one negative control (without liver DNA), and incubated each replicate set at either $12{ }^{\circ} \mathrm{C}$ or $25^{\circ} \mathrm{C}$. After 1,3 and 7 days of incubation we retrieved subsamples and centrifuged for $10 \mathrm{~min}$ at $10,000 \mathrm{rpm}$. DNA was extracted from the pellet as described above and supernatant was kept for DNase activity assay (see below).

DNA quality was tested as the capacity to amplify three different sizes of nuclear DNA (as in Höss et al. 1996). We used primers TuWZF (5'CGYCAGTTTCCYTTTCAGGTA-3')/TuZR (350 bp), TTT1 (220 bp) and TTD6 (130 bp). Amplification success was ranked from 0 to 3 , according to the number of positive PCR products. Negative controls were tested with TTD6, which amplifies the smallest DNA fragment and should be less sensitive to DNA degradation.

DNase activity was estimated according to Ruiz et al. (2000) using $2 \mu \mathrm{l}$ of supernatant and $2 \mu \mathrm{g}$ of herring DNA (Sigma). In negative and positive controls, the supernatant was replaced by nanopore water or $1 \mathrm{U} / \mu \mathrm{l}$ DNaseI (Fermentas), respectively. After one hour at $37{ }^{\circ} \mathrm{C}$, samples were run on $1 \%$ agarose gels and marked " 2 " (no DNA), "1" (smear) and "0" (no degradation). Results were tested for significance by ordinal logistic regression for DNA quality and DNase activity with JMP5.01 (SAS Institute).

\section{Results and discussion}

We successfully amplified $69 \%$ of the samples using TTT1 primers after the first extraction, and success reached $99 \%$ when the extraction was repeated up to 4 times. Only one sample out of the 85 analysed could not be sexed, possibly due to DNA degradation. The probability of exact genotyping, estimated using computer simulations, was $98 \%$ with a reasonable number of repetitions (5). PI values were low enough to assume that levels of chance matches were negligible, thus allowing for individual identification (Table 1). The error rates, averaged over 11 loci, were estimated to $21 \pm 6 \%$ ADO and $3 \pm 2 \%$ FA (Table 1 ). These values are in the upper range of that generally found in omnivores and carnivores (reviewed in Broquet and Petit 2004). Since most PCR inhibitors are glycolipids of vegetal origin (e.g. Monteiro et al. 1997), we can speculate that this could partially explain the high ADO rate in capercaillie, a species with a predominant vegetable-based adult diet. Clearly, the variation in genotyping reliability may depend on several other factors, including the sampling procedure, environmental conditions during sampling, extraction and amplification protocols, error rate estimation methods, and seasonal dietary variation (e.g. Maudet et al. 2004).

In our experimental analysis of factors effecting DNA quality, we found a significant difference among the 4 treatments (ordinal logistic regression, $\left.\quad \chi_{8,91}^{2}=116.52, \quad P<0.001\right)$. Our results showed that in moist conditions enzymatic and biotic factors were the principal causes for rapid DNA degradation (within $24 \mathrm{~h}$ ) at both temperatures (data not shown). In contrast, DNA quality remained high in hydrolysis and microbial treatments after 7 days at both temperatures.

Temperature and incubation time had no significant effect on global DNA quality. In addition, DNA quality and DNase activity were significantly correlated after one $\left(\chi_{4,24}^{2}=31.30\right.$, $P<0.0001)$, three $\left(\chi_{4,24}^{2}=21.06, P<0.001\right)$ and seven days $\left(\chi_{4,25}^{2}=35.47, P<0.0001\right)$. Based on these results, we advise that, to avoid nucleolytic 


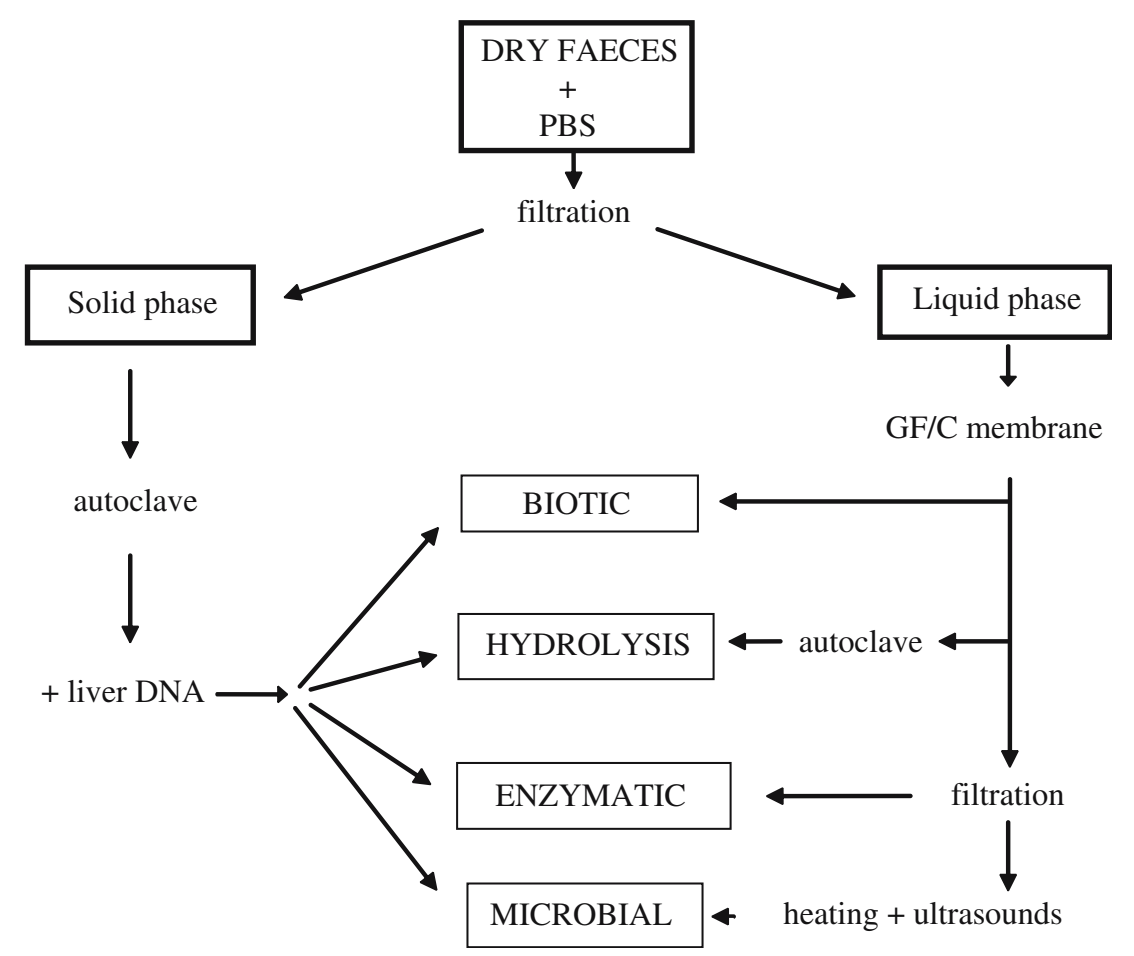

Figure 1. DNA degradation experiments. See text for details.

activity, samples are rapidly dessicated after sampling and are stored dry.

The high reliability of genotyping with DNA from faeces indicates that non-invasive sampling of avian populations can be successful. We suggest that pilot studies to investigate genotyping errors, and to identify optimal sampling strategies and preservation methods, should be considered before starting a large-scale genetic study using DNA from faeces.

\section{Acknowledgements}

We are indebt to T. Broquet, R. Hammond, P. Taberlet and N. Valière for helpful discussions and valuable comments on the manuscript. We also thank C. Decoster, I. Py, M. Rosset (Bern Zoological Garden) and C. Salamin.

\section{References}

Broquet T, Petit E (2004) Quantifying genotyping errors in noninvasive population genetics. Mol. Ecol., 13, 3601-3608.
Caizergues A, Dubois S, Loiseau A, Mondor G, Rasplus JY (2001) Isolation and characterization of microsatellite loci in black grouse (Tetrao tetrix). Mol. Ecol. Notes, 1, 36-38.

Fridolfsson AK, Ellegren H (1999) A simple and universal method for molecular sexing of non-ratite birds. J. Avian Biol., 30, 116-121.

Goudet J (1995) FSTAT (vers 1.2): a computer program to calculate $F$-statistics. J. Hered., 86, 485-486.

Höss M, Jagura P, Zastawny TH, Dizdaroglu M, Pääbo S (1996) DNA damages and DNA sequences retrival from ancient tissues. Nucleic Acids Res., 24, 1304-1307.

Maudet C, Luikart G, Dubray D, Von Hardenberg A, Taberlet $P$ (2004) Low genotyping error rates in wild ungulate faeces sampled in winter. Mol. Ecol. Notes, 4, 772-775.

Monteiro L, Bonnemaison D, Vekris A, Petry KG, Bonnet Jo, Vidal R, Cabrita Jo, Megraud FA (1997) Complex polysaccharides as PCR inhibitors in feces: Helicobacter pylori model. J. Clin. Microbiol., 35, 995-998.

Ruiz TR, Andrews S, Smith GB (2000) Identification and characterisation of nuclease activity in anaerobic environmental samples. Can. J. Microbiol., 46, 736-740.

Segelbacher G, Paxton RJ, Steinbrück G, Trontelj P, Storch I (2000) Characterization of microsatellites in capercaillie Tetrao urogallus (Aves). Mol. Ecol., 9, 1934-1935.

Segelbacher G, Steinbrück G (2001) Bird faeces for sex identification and microsatellite analysis. Vogelwarte, 41, 139-142.

Taberlet P, Griffin S, Goossens B, Questiau S, Manceau V, Escaravage N, Waits LP, Bouvet J (1996) Reliable genotyping of samples with very low DNA quantities using PCR. Nucleic Acids Res., 24, 3189-3194. 
Taberlet P, Waits LP, Luikart G (1999) Noninvasive genetic sampling: look before you leap. Trends Ecol. Evol., 14, 323327.

Valière N (2002) GIMLET: A computer program for analysing genetic individual identification data Mol. Ecol. Notes, 2, 377-379.
Valière N, Berthier P, Mouchiroud D, Pontier D (2002) Gemini: software for testing the effects of genotyping errors and multitubes approach for individual identification. Mol. Ecol. Notes, 2, 83-86. 